\title{
Editorial: Climate, Land Use, and Fire: Can Models Inform Management?
}

\author{
John T. Abatzoglou ${ }^{1 *}$, Gitta Lasslop ${ }^{2}$ and Dominique Bachelet ${ }^{3}$ \\ ${ }^{1}$ Management of Complex Systems, University of California, Merced, Merced, CA, United States, ${ }^{2}$ Max-Planck-Institute for \\ Meteorology, Hamburg, Germany, ${ }^{3}$ Department of Biological and Ecological Engineering, Oregon State University, Corvallis, OR, \\ United States
}

Keywords: fire, disturbance, management, climate change, simulation models, actionable science, science communication and strategic communication

Editorial on the Research Topic

Climate, Land Use, and Fire: Can Models Inform Management?

\section{INTRODUCTION}

Changes in fire regimes, including changes in fire intensity, frequency, and seasonality have resulted from anthropogenic activities including shifts in land use, land management practices, urbanization of the wildlands, and human-caused climate change (e.g., Bowman et al., 2020; Coop et al., 2020). The clear human fingerprint on fire activity in many regions (Archibald et al., 2013) indicates that landscape management may alter the trajectory of fire regimes in a changing climate. This hopeful call to action requires a sound understanding of landscape management effects on across different fire regimes in the context of other human and biophysical factors. It is challenging to isolate the individual contributions of these factors given their diverse spatial and temporal footprints. However, a diversity of modeling efforts can be used to improve understanding of changing fire regimes, to assess vulnerability to societal and ecosystem values, and to help design and test effective management options that would mitigate undesirable outcomes (e.g., fire impacts to communities, degradation of air quality, change in ecosystem structure, feedbacks to global climate) while preserving many of the ecological benefits of fire. Recent trends in extreme fire seasons including the 2019-2020 Southeast Australian bushfires (Nolan et al., 2020) and the 2020 Western United States fires (Higuera and Abatzoglou, 2020) catalyze the need to deliver useful science-based information to decision-makers for devising effective adaptive strategies to reduce the impacts from future extreme fire seasons.

Humans have long influenced fire regimes, albeit in complex and heterogeneous ways (e.g., Pyne 1993). Land use changes have continued in recent decades as agricultural expansion and intensification have reduced burned area in grasslands and savannas (e.g., Andela et al., 2017), while land exploitation and deforestation have increased fire occurrence in peatlands (e.g., Normile 2019) and forests (e.g., Escobar 2019). While fire is a biophysical process, human behavior and decisions drive many global fire regimes and changes thereof. Humans dictate many fire regimes though a number of vehicles: adding ignitions in places and at times of year that ecosystems have not been subject to in the past (e.g., Syphard and Keeley 2014; Balch et al., 2017); introducing invasive species that cause surface fuel continuity where patchiness prevented fire spread (e.g., Brooks et al., 2004); suppressing fire thereby allowing for fuel accumulation and expansion of fire sensitive species (e.g., Novacki and Abrams 2008); establishing fire-prone homogeneous tree plantations (e.g., Zald and Dunn 2018); and expanding the wildland urban interface (e.g., Mietkiewicz et al., 2020). Human 
migration as a result of climate change, economics, and local conflicts for dwindling resources (e.g., Cattaneo et al., 2019) suggest continued changes in human fingerprint on fire regimes across much of the planet.

\section{SYNTHESIS OF STUDIES}

This Research Topic included seven articles that used a diversity of modeling approaches to assess how climate, land use, and other anthropogenic factors influence fire regimes to inform managers and land stewards. Studies focused on different fire prone environments across the globe from Brazil to the southwestern United States and Canada, from southeastern Australia to the Mediterranean basin. Because fire impacts vary widely across ecosystems, geographies and scales, a hierarchy of modelling approaches is required to meet the different goals of fire management, for instance reduction of fire risk, conservation of threatened ecosystem types and biodiversity, increase in carbon storage, or mitigation of anthropogenic climate change. The contributions that constitute this Research Topic highlight both a search for better understanding of fire-ecosystem responses to a constellation of anthropogenic factors and the development of vehicles that deliver usable information and tools to land managers and decision makers preparing for both the next fire season as well as that of the next several decades.

Since fuels reduction is a hot topic issue and is often brandished as the one size fits all solution to the extreme fire behavior, we highlight two articles (Clarke et al., 2020; O'Connor et al., 2020) that show the importance of fuels reduction in one dryland ecosystem and the only short term success in another. A second grouping of studies highlighted the various ways in which modeling can more broadly inform management decisions, including a review of various modeling efforts to help managers assess and address ecosystem stability (Loehman et al., 2020), the identification of non-stationarity in extreme fire seasons that emphasizes the need for modernizing fire risk approaches (Barbero et al., 2020), and the importance of ecosystem threshold behavior in savanna ecosystems to changing fire frequency that will require agile models forecasting such drastic change in conditions (Gomes et al., 2020). Two final papers highlight next steps for the fire modeling community: the well known goal of improving earth system models that are used to simulate future climate and could be used to assess the climate mitigation potential of fire management to inform international policy (D'Onofrio et al., 2020); the potential of linking fire regime characteristics with fire management decisions in modeling efforts to create more useful tools to address the challenges ahead (Taylor 2020).

\section{Influence of Fuel Reduction Efforts}

Clarke et al. (2020) used a pyrogeographic approach and machine learning to compare the influence of four fundamental switches (fuel load, fuel dryness, fire weather, and ignitions) on large fire probability across both forests and grasslands in southeastern Australia. They found nonlinear responses-notably with increased fuel dryness in forested environments. Furthermore, a reduction in fuel load from 24 to $16 \mathrm{tha}^{-1}$ in forests yielded a $50 \%$ decrease in large fire probability. Their results suggest that landscape-scale reductions in fuel load-well in excess of levels currently applied-have the potential to ameliorate the climate change-driven rise in the probability of large forest fires.

O'Connor et al. (2020) simulated the interactions of climate, fire, and active management along an ecological gradient of shrublands, woodlands, and forests on a mountain range in Arizona. Their results showed the overwhelming impacts of climate change in arid environments with or without disturbance. Desert grassland and shrub communities were maintained or even expanded while woodland and forests receded to climate refugia sites regardless of management actions. Recommended fuel treatments showed potential to mitigate the severity of fire effects and to slow the transition from forest to shrubland but without preventing it entirely.

\section{Tying Modeling Results With Management Decisions}

Loehman et al. (2020) described three modeling approaches applicable for land management: historical comparisons to create a frame of reference, future comparative modeling to explore plausible futures, and threshold detection modeling to warn managers about possible loss of ecosystem stability. As rapid climate change alters disturbance regime limiting the usefulness of looking back at previous behaviors and likely overwhelming current land management strategies, they emphasize the critical need for collaboration between modelers and field ecologists to integrate local knowledge that describes emerging novel ecosystems.

Barbero et al. (2020) quantified changes in fire weather conditions including extreme fire seasons imparted by anthropogenic climate change over France. Using counterfactual simulations that excluded first-order estimates of modeled changes in climate, they estimated that $47-72 \%$ of the observed trends in various fire weather indices across Mediterranean France during 1958-2017 were attributable to anthropogenic climate change. Finally, they demonstrated that climate change has significantly altered the probability of extreme fire seasons. For example, fire weather conditions similar to those observed during the extreme 2003 fire season were estimated to be 25 times more likely today compared to pre-industrial climate. This work highlights the importance of modernizing fire risk proxies during an era of changing environmental conditions.

Gomes et al. (2020) investigated the responses of plant biomass to frequent fires in the Brazilian savanna (Cerrado). The biennial fire use in agricultural practices is also a source of ignition for the surrounding natural vegetation. They used the BEFIRE (Behaviour and Effect of Fire) model which includes relationships between fire frequency, plant biomass and fire emissions based on data compiled from experimental burnings in the Cerrado region. The study showed that under biennial fire regimes only herbs and grasses were able to recover most of their biomass between fire events, while such a regime led to degradation and the altered coexistence of the different plant 
types in shrub and tree ecosystems. The model simulations should inform fire management to increase the resilience of the threatened biome.

\section{Next Steps for Modeling}

D'Onofrio et al. (2020) evaluated dynamic global vegetation models using remote sensing data in terms of the vegetationclimate-fire relationships. By analyzing these relationships it was possible to critique model structures and inform development options based on model-data comparison. Possible improvements related to the representation of fire, drought and grass-tree competition were identified to improve models used for future projections of vegetation and the carbon cycle as well as in Earth System Models. The representation of fire in such models is important to understand the effects of changing fire regimes but also the potential influence of human fire management on future climate and ecosystem properties.

Taylor (2020) investigated the relationship between wildfire activity and management decisions across spatio-temporal scales in Canada. Time series analysis methods were applied to investigate the temporal scales of fire weather and activity while fire management decision problems were identified through interviews with fire management agencies. The scales of fire activity were connected to the spatio-temporal dimensions of fire management decisions, e.g., the larger spatio-temporal scales of area burned or fire frequency matched the spatiotemporal scales of resource capacity while the scales of resource utilization were close to the scales that matter for fire spread. The results implied that the different areas of fire planning needed to take into account different aspects of fire regime changes. Taylor proposed that this framework relating the scales of fire activity to fire management decisions could be extended to include mechanisms such as increasing atmospheric $\mathrm{CO}_{2}$.

\section{REFERENCES}

Andela, N., Morton, D. C., Giglio, L., Chen, Y., Van Der Werf, G. R., Kasibhatla, P. S., et al. (2017). A human-driven decline in global burned area. Science 356 (6345), 1356-1362. doi:10.1126/science.aal4108

Archibald, S., Lehmann, C. E. R., Gómez-Dans, J. L., and Bradstock, R. A. (2013). Defining pyromes and global syndromes of fire regimes. Proc. Natl. Acad. Sci. Unit. States Am. 110, 6442-6447. doi:10.1073/pnas.1211466110

Balch, J. K., Bradley, B. A., Abatzoglou, J. T., Nagy, R. C., Fusco, E. J., and Mahood, A. L. (2017). Human-started wildfires expand the fire niche across the United States. Proc. Natl. Acad. Sci. U.S.A. 114, 2946-2951. doi:10.1073/pnas. 1617394114

Barbero, R., Abatzoglou, J. T., Pimont, F., Ruffault, J., and Curt, T. (2020). Attributing increases in fire weather to anthropogenic climate change over France. Front. Earth Sci. 8, 104. doi:10.3389/feart.2020.00104

Bowman, D. M., Kolden, C. A., Abatzoglou, J. T., Johnston, F. H., van der Werf, G. R., and Flannigan, M. (2020). Vegetation fires in the anthropocene. Nat. Rev. Earth Environ. 1 (10), 500-515. doi:10.1038/s43017-020-0085-3

Brooks, M. L., D’Antonio, C. M., Richardson, D. M., Grace, J. B., Keeley, J. E., DiTomaso, J. M., et al. (2004). Effects of invasive alien plants on fire regimes. Bioscience 5 (7), 6770-688. doi:10.1641/0006-3568(2004)054[0677:eoiapo]2.0.co;2

Cattaneo, C., Beine, M., Fröhlich, C. J., Kniveton, D., Martinez-Zarzoso, I., Mastrorillo, M., et al. (2019). Human migration in the era of climate change. Rev. Environ. Econ. Pol. 13 (2), 189-206. doi:10.1093/reep/rez008

\section{CONCLUDING REMARKS}

Continued efforts are needed to understand the roles played by top-down climate factors and bottom-up land-management in the tapestry of changing global fire regimes. Investigating different scenarios of human activities, including management, may be as important as investigating climate scenarios to understand the potential and the boundaries of the human leverage. Integration of scientific understanding with practitioners' local knowledge is the key to develop effective management strategies for different landscapes at actionable scales to achieve desirable fire regime outcomes (e.g., reduced fire risks, conservation of ecosystem services)-particularly under otherwise non-stationary environmental and societal conditions. Studies such as those highlighted in this Research Topic showcase that models provide advances in understanding and provide outcomes that can inform management while being critically challenged and improved by collaborations with field practitioners. Ongoing changes in environmental and societal landscapes and their collective impacts on fire regimes reinforces the need to develop tools that provide guidance how fire management can be used to mitigate fire risk. Bringing together modelers, field ecologists, managers, and practitioners to share their respective knowledge will not only facilitate the development of effective adaptation strategies but also create better science. As Thomas Kuhn simply stated it, the answers you get depend upon the questions you ask and managers do have many questions for the scientists.

\section{AUTHOR CONTRIBUTIONS}

All authors wrote, edited, and reviewed the submission.

Clarke, H., Penman, T., Boer, M., Cary, G. J., Fontaine, J. B., Price, O., et al. (2020). The proximal drivers of large fires: a pyrogeographic study front. Earth Sci. 890. doi:10.3389/feart.2020.00090

Coop, J. D., S. A., Parks, C. S., Stevens-Rumann, S. D., Crausbay, Higuera, P. E., Hurteau, M. D., et al. (2020). Wildfire-driven forest conversion in western north American landscapes, Bioscience 70 (8), 659-673. doi:10.1093/biosci/ biaa061

D’Onofrio, D., Baudena, M., Lasslop, G., Nieradzik, L. P., Wårlind, D., and von Hardenberg, J. (2020). Linking vegetation-climate-fire relationships in subsaharan africa to key ecological processes in two dynamic global vegetation models front. Environ. Sci. 8, 136. 10.3389/fenvs.2020.00136

Escobar, H. (2019). There's no doubt that Brazil's fires are linked to deforestation, scientists say. Science (Washington, DC: American Association for the Advancement of Science. doi:10.1126/science.aaz2689

Gomes, L., Miranda, H. S., Soares-Filho, B., Rodrigues, L., Oliveira, U., and Bustamante, M. M. C. (2020). Responses of Plant Biomass in the Brazilian Savanna to Frequent Fires. Front. For. Glob. Chang. 3. doi:10.3389/ffgc. 2020.507710

Higuera, P. E., and Abatzoglou, J. T. (2020). Record-setting climate enabled the extraordinary 2020 fire season in the western United States. Global Change Biol. doi:10.1111/gcb.15388

Loehman, R. A., Keane, R. E., and Holsinger, L. M. (2020). Simulation modeling of complex climate, wildfire, and vegetation dynamics to address wicked problems in land management. Front. For. Glob. Chang. 3 (3). 10.3389/ffgc.2020.00003. 
Mietkiewicz, N., Balch, J. K., Schoennagel, T., Leyk, S., St. Denis, L. A., and Bradley, B. A. (2020). In the line of fire: consequences of human-ignited wildfires to homes in the U.S. (1992-2015). Fire 3 (3), 50. doi:10.3390/ fire 3030050

Nolan, R. H., Boer, M. M., Collins, L., Resco de Dios, V., Clarke, H., Jenkins, M., et al. (2020). Causes and consequences of eastern Australia's 2019-20 season of mega-fires. Global Change Biol., 26 (3), 1039-1041. doi:10.1111/gcb.14987

Normile, D. (2019). "Indonesia's fires are bad, but new measures prevented them from becoming worse," Science (Washington, DC: American Association for the Advancement of Science. doi:10.1126/science.aaz7020

Nowacki, G. J., and Abrams, M. D. (2008). The demise of fire and "mesophication" of forests in the eastern United States. Bioscience 58 (2), 123-138. doi:10.1641/ b580207

O'Connor, C. D., Falk, D. A., and Garfin, G. M. (2020). Projected climate-fire interactions drive forest to shrubland transition on an Arizona sky island front. Environ. Sci. 8, 137, 2020 Available at: https://www.frontiersin.org/article/10. 3389/fenvs.2020.00137.

Pyne, S. J. (1993). "Keeper of the flame: a survey of anthropogenic fire," in Fire in the environment: its ecological, climatic, and atmospheric chemical importance. Editors Crutzen P. J. and Goldammer J. G. (New York, NY: John Wiley and Sons), 245-266.
Syphard, A., and Keeley, J. (2014). Location, timing and extent of wildfire vary by cause of ignition. Int. J. Wildland Fire 24 (1), 37-47. doi:10.1071/WF14024

Taylor, S. W., (2020). Atmospheric cascades shape wildfire activity and fire management decision spaces across scales-a conceptual framework for fire prediction. Front. Environ. Sci. 8. doi:10.3389/fenvs.2020.527278

Zald, H. S. J. and Dunn, C. J. (2018). Severe fire weather and intensive forest management increase fire severity in a multi-ownership landscape. Ecol. Appl. 28, 1068-1080. doi:10.1002/eap.1710

Conflict of Interest: The authors declare that the research was conducted in the absence of any commercial or financial relationships that could be construed as a potential conflict of interest.

Copyright (C) 2020 Abatzoglou, Lasslop and Bachelet. This is an open-access article distributed under the terms of the Creative Commons Attribution License (CC BY). The use, distribution or reproduction in other forums is permitted, provided the original author(s) and the copyright owner(s) are credited and that the original publication in this journal is cited, in accordance with accepted academic practice. No use, distribution or reproduction is permitted which does not comply with these terms. 